\title{
Design and Simulation of Isolation Room for a Hospital
}

\author{
Simeon Jacob, Siddharth Singh Yadav and Basant Singh Sikarwar
}

\begin{abstract}
Heating, ventilation and air conditioning (HVAC) of hospitals is a highly specialized field and critical care units like isolation rooms and operation theatres deserve special attention, as infected patients must be isolated from ambient environment in order to prevent the infection from spreading and to save the life of the patient. This manuscript aims to optimize the ventilation strategy towards contaminant suppression in the isolation room. 3D Navier-Stokes and energy equation using finite volume method (FVM) with a domain of isolation room is solved for appropriate boundary conditions. The patient's body is approximated as a semi-cylindrical shape resting on a bed and is treated as a constant heat source. Velocity and temperature profile inside the isolation room for various configurations are simulated. Our results suggest that immune-suppressed patients should be kept near the air supply and infectious patients near the exhaust.
\end{abstract}

Keywords Nosocomial - Infection - Isolation • Ventilation • Air conditioning • CFD · Simulation

\section{Introduction}

The later stage of twentieth century witnessed an alarming spread of Tuberculosis (TB) across the European nations, and this sparked an extensive research in the field of infection control techniques [1]. This led to development in the field of infection suppression in order to reduce the spread of disease. A logical solution to the problem was isolation of the infected patient. Deadlier threats like AIDS, bioterrorism (anthrax attacks, Tokyo Metro Sarin Gas attack etc.) and SARS have triggered many concerns about the control of the indoor environment and unveiled the role of ventilation system design in isolating an infected or vulnerable patient [2].

S. Jacob $(\bowtie) \cdot$ S. S. Yadav · B. S. Sikarwar

Department of Mechanical Engineering, Amity University Uttar Pradesh,

Noida, India

e-mail: simeonjacob24@gmail.com

P. Saha et al. (eds.), Advances in Fluid and Thermal Engineering,

Lecture Notes in Mechanical Engineering,

https://doi.org/10.1007/978-981-13-6416-7_8 
More recent global outbreaks like swine flu, bird flu and Ebola virus have shown that even though we have advanced technologically, there is still a lot left to be done in the field of contaminant suppression [3].

Medical facilities are places where relatively high levels of pathogenic (disease-causing) micro-organisms are generated and concentrated by an infected patient population or by procedures that handle infected human tissues and bodily fluids. These pathogens are spread by a number of contact and noncontact (airborne) causes. Hospital-acquired infections (HAIs, also referred to as nosocomial infections) have a significant impact on patient care. Mortality rates from HAIs are significant and affect the overall cost of healthcare delivery. It is agreed that 80 $90 \%$ of HAIs are transmitted by direct contact, with $10-20 \%$ resulting from an airborne transmission (representing $0.4-1 \%$ of admitted patients) [4]. It is, therefore, imperative that we take a closer look at the design of healthcare facilities with respect to suppression of contaminants while at the same time providing patient comfort to ensure that the patient does not get worse after admission and leaves the facility healthy. For achieving this goal, the design of the heating, ventilation and cooling (herein referred to as HVAC) system of a healthcare facility is important and has to be economically viable. The term is often used interchangeably with the more common 'air conditioning'. The term air conditioning refers to a system that controls temperature, moisture in the air (humidity), supply of outside air for ventilation, filtration of airborne particles, and air movement in the occupied space. HVAC systems in healthcare facilities provide a broad range of services in support of populations who are uniquely vulnerable to an elevated risk of health, fire and safety hazard. The role of the HVAC system in life safety and infection control becomes more important with increasing complexity of the medical services provided and the acuity of illness of the patient population [5].

Isolation refers to the separation of a seriously ill patient to stop the spread of infection or protect the patient from irritating factors. A patient known or suspected to harbour transmissible micro-organisms should be placed in a single room. A single room with appropriate air handling and ventilation is particularly important for reducing the risk of airborne transmission of micro-organisms from a source patient to susceptible patients and other persons in hospitals. Airborne transmission is just one of the means by which nosocomial infection spreads. Other modes of infection include contact, droplet, common vehicle and vector-borne. An isolation room is designed and provided with all the facilities that are required to ensure protection from all the above-mentioned modes of transmission of infectious microbes. Standard isolation rooms have a pan sanitizer near the room, a staff hand-wash basin within the room, an en suite bathroom, a self-closing door, a label as a standard isolation room. The most predominant mode of infection communication, i.e. airborne transmission is taken care of by an appropriate HVAC system. Broadly speaking, there are two classes of isolation rooms: Class $\mathrm{N}$-negative pressure room and Class $\mathrm{P}$-positive pressure room [6]. Negative pressure rooms are for patients who are suffering from infectious or contagious diseases like TB and SARS. The aim of placing infected persons in negative pressure rooms is to reduce transmission of disease via the airborne route. Conroy et al. [7] came up with a list 
of features, which should exist in a negative pressure room to effectively isolate the patient. Positive pressure rooms are installed in certain facilities to isolate profoundly immune-compromised patients, such as those suffering from AIDS. A lot of research has hence been focussed towards the design of isolation wards with respect to ventilation strategy for contaminant suppression and patient comfort.

A patient in an uncomfortable environment is exposed to thermal stress that may hinder the body's ability to properly regulate body heat, interfere with rest and be psychologically harmful. As per healthcare guidelines $[8,9]$, ventilation strategy in an isolation room should be such that there are no stagnant and under-ventilated areas where infectious particles might be accumulated. In addition, healthcare providers subjected to an uncomfortable environment may not function at peak performance levels [5]. A study [8] of isolated patients concluded that healthcare workers visited patients in contact isolation less often than they visited regular patients, which might compromise patient safety and healthcare quality. Keeping this in mind, a proper ventilation strategy must be devised which provides for infection control and mitigation, comfort of both patients and healthcare providers, and efficient power consumption.

As such, there are many challenges to overcome in the design of an efficient HVAC system for contaminant suppression. The initial design problem of an isolation room is to fix a location of the supply and exhaust vents inside the isolation room. Cheong and Phua [10] proposed a ventilation strategy for effective removal of pollutant from hospital isolation wards and inferred that a low-lying exhaust together with a ceiling supply duct delivering laminar air was the best combination. The role of air changes per hour $(\mathrm{ACH})$ in order to reduce the effective residence time of contaminant was also of prime research interest. Memarzadeh and $\mathrm{Xu}$ [11] investigated the role of air changes per hour in possible transmission of airborne infections by simulating various ventilation system configurations and concluded that the dominant factor that affects the transmission and control of contaminants is the path between the contaminant source and exhaust, and not the airflow ventilation rate as was expected. This observation was also corroborated experimentally by Mousavi and Grosskopf [12] and Walker et al. [13]. More in-depth studies on the path of a contaminant inside an isolation ward and its response to various strategies have been carried out. Tung et al. [14] carried out a study on contaminant (sulphur hexafluoride, SF6) dispersion inside isolation room by varying the room negative pressure (from -2.5 to $-15.0 \mathrm{~Pa}$ ), the ventilation rates $\left(12\right.$ and $24 \mathrm{~h}^{-1}$ ), by factoring in the local air quality index, and the exposure index of hospital workers. Derakshan and Shaker [15], in an attempt to reduce energy consumption by increasing the efficiency of natural ventilation, investigated volumetric flow rate in a building for various aspect ratios of the windows and their locations for various wind directions. Wan et al. [16] proposed a new method for selecting optimum indoor temperature and relative humidity to achieve minimum energy consumption for a required indoor thermal comfort level, which is evaluated with effective temperature. The research into contaminant suppression can be further extended to general hospital wards in order to reduce HAIs. Beggs et al. [17] conducted research into the need of ventilation system inside general multi-bed hospital wards. 
They found that bio-aerosol concentration was least when the supply and exhaust were ceiling mounted as opposed to other strategies.

Chung et al. [18] studied the different ventilation patterns arranged by two outlet and two inlet diffusers at various locations. A three-dimensional k- $\varepsilon$ turbulence model using a finite difference code (UNIC), which was developed by Engineering Science Inc., USA, was adopted in this work. The numerical simulation was first adopted to predict the airflow patterns and ventilation performance and later, a laboratory experiment at room air and contaminant distribution in a full-scale test chamber was conducted to validate the simulation results. The results indicated that the location of inlet and outlet diffusers severely affected the ventilation efficiency. The arrangement of inlet/outlet diffusers can cause different flow recirculation patterns, and this may change the mean age of indoor contaminant, thus deciding how quickly the indoor contaminant can be removed. Yu et al. [19] conducted a study on ventilation strategies for hospitals to mitigate the risk of infections. They studied the effects of location of infected patients and air change per hour to minimize deposition and floating time of airborne virus particles while maximizing energy efficiency. Although there is a plethora of research [7-15, 17, 18, 20-23] on making contaminant removal systems efficient and optimizing power consumption in buildings, a comprehensive research that amalgamates effective ventilation systems with infection control in isolation wards of hospitals has a long way to go.

In this background, the manuscript is to be used as a basis to set up a more advanced study on the subject of contaminant suppression and HVAC design. Here, we intend to understand the effect of placement of air supply and exhaust vents on the fluid flow and temperature profile inside the isolation ward. Our research intends to develop the existing theories and put forward an inclusive solution to the problem of HVAC design of an isolation ward keeping all the above factors in mind. The model for various orientation of air supply and exhaust vents of the isolated room was developed and simulation was carried out using in-house CFD solver. Details of CFD solver were reported elsewhere [24].

\section{Computational Model and Solution Methodology}

The physical domains in this work are for an isolation room of a hospital. It can be any ordinary room in a hospital, which is spacious enough for a patient, care provider/s, various equipment, etc. Figure 1 shows the complete flow diagram of our study. In unidirectional flow, the air supply and exhaust vent are on opposite walls. However, the position of patient bed is varied. In multi-directional flow, air supply inlets are placed on the ceiling, and exhaust on the sidewall close to the patient bed. Figure 2 shows the schematic diagram of various ventilation schemes, which are to be analysed. The isolation room studied in this work has the dimensions $4.88 \mathrm{~m} \times 3.60 \mathrm{~m} \times 3.05 \mathrm{~m}$. The ventilation rate is taken as twelve air change per hour $(\mathrm{ACH})$ which is equivalent to $0.1812 \mathrm{~m}^{3} \mathrm{~s}^{-1}$ as recommended in literature [25-29]. For the case of simplicity, the infiltration of air through the door 
and windows and the radiation effects have not been taken into consideration, and as such it is considered logical to hypothesize the room as one without any door or window.

For the unidirectional flow cases, high sidewall supply opening is provided on one wall and the exhaust is positioned $0.3048 \mathrm{~m}$ above the floor on the opposite sidewall. The dimensions of inlet and exhaust vents for the unidirectional flow case are $1.0668 \mathrm{~m} \times 0.4572 \mathrm{~m}$. This ensures an inlet velocity of $0.3716 \mathrm{~m} \mathrm{~s}^{-1}$ [29]. The patient's body is approximated as a cylinder $0.3048 \mathrm{~m}$ in diameter. The bed is placed at a height of $0.4572 \mathrm{~m}$ from the ground. In case-1, the bed is $0.9144 \mathrm{~m}$ away from the air supply sidewall, whereas in case-2, the bed is near the exhaust sidewall as shown in Fig. 2a, b, respectively. Furthermore, the location of the air supply duct in cases 1 and 2 is lowered along the wall and the changes in flow pattern and temperature profile across the room are analysed. In this manner, two sub-cases for two locations of the air supply duct are studied in both the bed configurations of the isolation room. In all the cases, the temperature of the supply air is held constant at $300 \mathrm{~K}$; the inlet velocities are constant for the cases 1 and 2 .

The third case is that of a mixed-ventilation system-multi-directional flow. It consists of multiple inlet vents strategically located on the ceiling and an exhaust vent near the patient's bed as shown in Fig. 2c. The inlet vents are of size $0.6096 \mathrm{~m} \times 0.2286 \mathrm{~m}$. The ACH rating is maintained at 12 air changes. However, to ensure proper mixing of air inside the domain, high momentum air is to be supplied. That is, the inlet velocity is $0.46 \mathrm{~m} \mathrm{~s}^{-1}$. The patient's body is directly under one of the supply openings, but it is ensured that the face/head of the patient does not receive the impinging jet of the supply air. The other two vents are located symmetrically on two sides of the central air supply vent.

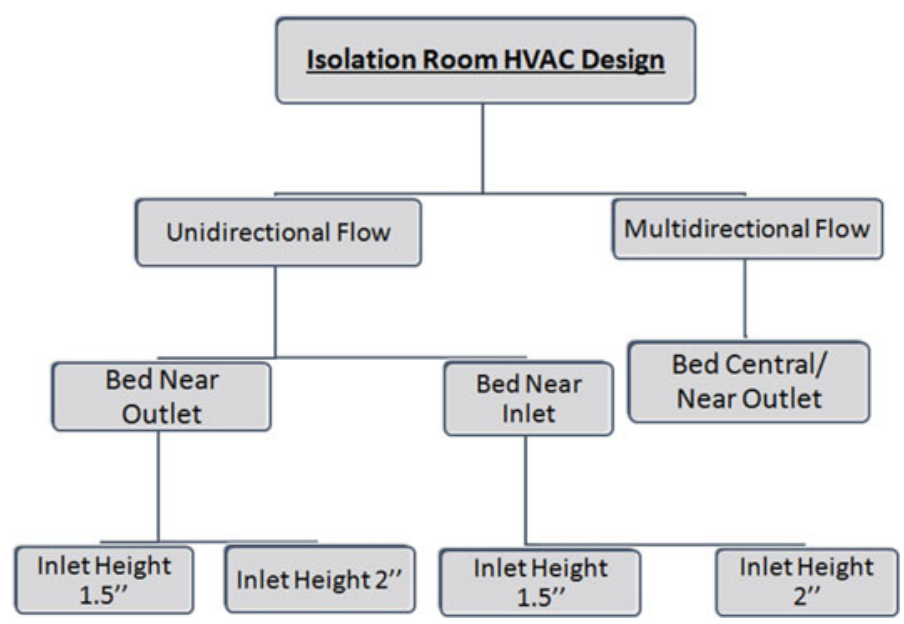

Fig. 1 Flow diagram of study carried in present work 
(a)

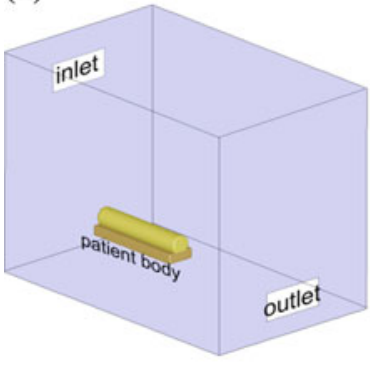

(b)

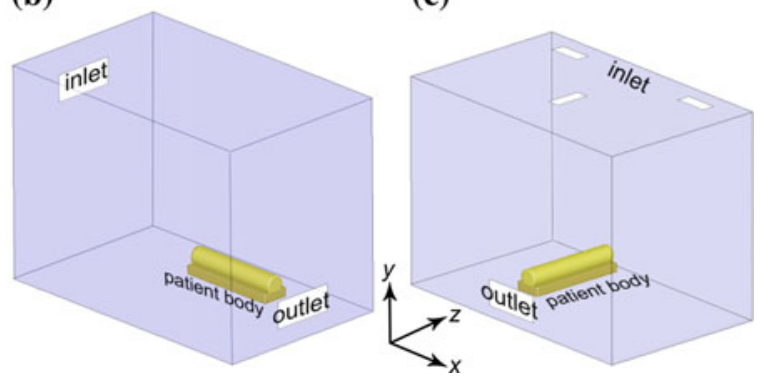

Fig. 2 Schematic diagram of isolation room with bed and body of the patient. a Case-1: unidirectional flow and bed close to air supply inlet. b Case-2: unidirectional flow and bed close to air outlet and c Case-3: multi-directional flow bed position close to the outlet

Table 1 Thermo-physical properties of the computational domain

\begin{tabular}{l|l|l|l|l|l}
\hline Domain & Material & $\begin{array}{l}\text { Density } \\
\mathrm{Kg} \mathrm{m}^{-3}\end{array}$ & $\begin{array}{l}\mathrm{C}_{\mathrm{P}} \\
\mathrm{J} \mathrm{Kg}^{-1} \mathrm{~K}^{-1}\end{array}$ & $\begin{array}{l}\text { Thermal } \\
\text { conductivity } \\
\mathrm{W} \mathrm{m} \mathrm{K}^{-1}\end{array}$ & $\begin{array}{l}\text { Viscosity } \\
\mathrm{Kg} \mathrm{m}^{-1} \mathrm{~s}^{-1}\end{array}$ \\
\hline Fluid & Air & 1.225 & 1006.43 & 0.0242 & $1.789 \mathrm{E}-5$ \\
\hline Walls & $\begin{array}{l}\text { Calcium } \\
\text { carbonate }\end{array}$ & 2800 & 856 & 2.25 & - \\
\hline Bed & Wood & 700 & 2310 & 0.173 & - \\
\hline Body & $\begin{array}{l}\text { Approximate to } \\
\text { human bones }\end{array}$ & 1800 & 3470 & 0.45 & - \\
\hline
\end{tabular}

Approximations for Patient's Body: The patient's body is a constant source of sensible heat at roughly 70 watts of strength. This amounts to around $590 \mathrm{~W} \mathrm{~m}^{-3}$. It has been simulated as a cylinder $1.76 \mathrm{~m}$ in length and $0.3048 \mathrm{~m}$ in diameter. The density is taken as $1800 \mathrm{~kg} \mathrm{~m}^{-3}$, specific heat as $3470 \mathrm{~J} \mathrm{Kg}^{-1} \mathrm{~K}^{-1}$ and thermal conductivity as $0.34 \mathrm{~W} \mathrm{~m}^{-1} \mathrm{~K}^{-1}$ to simulate a material close enough to human flesh. The source of this data is the website of School of physics, University of Sydney [30]. For the sake of simplicity, no other heat source has been considered in the present work. The present study aims to simulate the human body in the presence of externally supplied conditioned air at $300 \mathrm{~K}$ and $50 \%$ relative humidity [31]. The problem is rendered transient and as such is solved until steady state is attained in terms of net heat exchange across the entire domain (Table 1).

\subsection{Mathematical Model}

The k- $\varepsilon$ model is amongst the most widely used turbulence models. The standard $\mathrm{k}-\varepsilon$ model is the simplest 'complete model' of turbulence in which the solution of 
two separate transport equations allows the turbulent velocity and length scales to be independently determined and it has become the workhorse of practical engineering flow calculations in the time since Launder and Spalding [32] proposed it. Robustness, economy and reasonable accuracy for a wide range of turbulent flows explain its popularity in industrial flow and heat transfer simulations.

The various conservation equations used in standard $\mathrm{k}-\varepsilon$ model are given hereunder:

$$
\begin{gathered}
\frac{\partial u_{i}}{\partial x_{i}}=0 \\
\frac{\partial u_{i}}{\partial t}+\frac{\partial u_{i} u_{j}}{\partial x_{j}}=-\frac{\partial}{\partial x_{i}}\left(\frac{P}{\rho}+\frac{2}{3} k\right)+\frac{\partial}{\partial x_{j}}\left[v_{t}+\left(\frac{\partial u_{i}}{\partial x_{j}}+\frac{\partial u_{j}}{\partial x_{i}}\right)\right] \\
\frac{\partial k}{\partial t}+\frac{\partial k u_{j}}{\partial x_{j}}=\frac{\partial}{\partial x_{j}}\left(\frac{v_{t}}{\sigma_{1}} \frac{\partial k}{\partial x_{j}}\right)+v_{t} S-\varepsilon \\
\frac{\partial \varepsilon}{\partial t}+\frac{\partial \varepsilon u_{j}}{\partial x_{j}}=\frac{\partial}{\partial x_{j}}\left(\frac{v_{t}}{\sigma_{2}} \frac{\partial \varepsilon}{\partial x_{j}}\right)+C_{1} \frac{\varepsilon}{k} v_{t} S-C_{2} \frac{\varepsilon^{2}}{k} \\
S=\left(\frac{\partial u_{i}}{\partial x_{j}}+\frac{\partial u_{j}}{\partial x_{i}}\right) \frac{\partial u_{i}}{\partial x_{j}}
\end{gathered}
$$

where $\sigma_{1}=1.0, \sigma_{2}=1.3, \sigma_{3}=1.0, C_{\mu}=0.09, C_{1}=1.44, C_{2}=1.92$.

This family of equations is generally known as the k- $\varepsilon$ model. In the present work, $\mathrm{k}-\varepsilon$ turbulence (two-equation) model is used for $3 \mathrm{D}$ simulation.

The standard $\mathrm{k}-\varepsilon$ is a semi-empirical model based on model transport equations for the turbulence kinetic energy $(k)$ and its dissipation rate $(\varepsilon)$. In this technique, the Reynolds stress is modelled in terms of two turbulence parameters, the turbulent kinetic energy, $k$ and the turbulent energy dissipation rate, $\varepsilon$ are defined below:

$$
\begin{gathered}
k=\frac{1}{2}\left(\overline{u^{\prime 2}}+\overline{v^{\prime 2}}+\overline{w^{\prime 2}}\right) \\
\varepsilon=v\left[\left(\frac{\partial u^{\prime}}{\partial x}\right)^{2}+\left(\frac{\partial u^{\prime}}{\partial y}\right)^{2}+\left(\frac{\partial u^{\prime}}{\partial z}\right)^{2}+\left(\frac{\partial v^{\prime}}{\partial x}\right)^{2}+\left(\frac{\partial v^{\prime}}{\partial y}\right)^{2}\right. \\
\left.+\left(\frac{\partial v^{\prime}}{\partial z}\right)^{2}+\left(\frac{\partial w^{\prime}}{\partial x}\right)^{2}+\left(\frac{\partial v^{\prime}}{\partial y}\right)^{2}+\left(\frac{\partial w^{\prime}}{\partial z}\right)^{2}\right]
\end{gathered}
$$




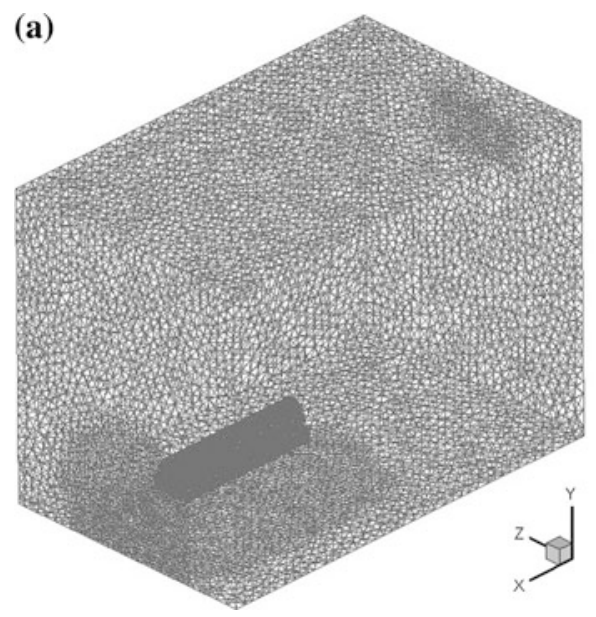

(b)

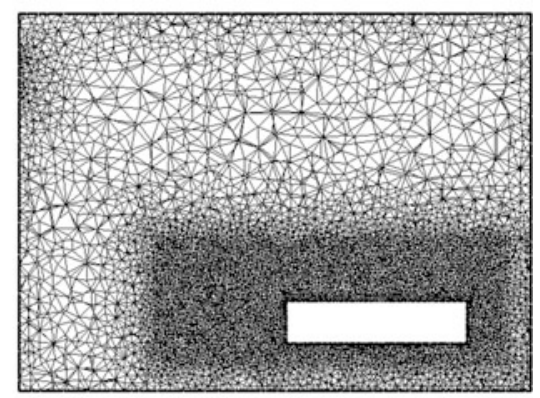

Fig. 3 Mesh on computational domain a isometric view $\mathbf{b}$ sectional view at $z=1.525 \mathrm{~m}$

where $\left(u^{\prime}, v^{\prime}, w^{\prime}\right)$ is the fluctuating velocity vector. $k$, the turbulent kinetic energy, is defined as the variance of the fluctuations in velocity. It has dimensions of (L2 T-2). $\varepsilon$, the turbulence eddy dissipation rate, is the rate at which the velocity fluctuations dissipate in a turbulent flow. It has dimensions of turbulent kinetic energy per unit time (L2 T-3). The kinetic energy is zero for laminar flow and can be as large as 5\% of the kinetic energy of the mean flow in a highly turbulent case.

The finite volume method (FVM) is adopted to solve the aforementioned Eqs. (1-8). The details of this method were reported by authors elsewhere [24]. In this method, the physical domain is subdivided into a number of contiguous control volumes on an unstructured tetrahedral grid, as shown in Fig. 3. Unstructured tetrahedral grids are constructed by dividing the computational domain into small cells that have a tetrahedral shape. The strength of this type of grid lies in its flexibility for handling very complex geometries. A commercial software package (ICEMCFD) was used to generate meshes. The generated mesh was made very fine near the patient body $(0.01 \mathrm{~m})$ and coarse towards the isolation room walls $(0.2 \mathrm{~m})$. A refined mesh was also generated at the air supply inlet and the exhaust. To effectively capture the air flow around the patient body, a mesh density box was generated with elements of size $0.025 \mathrm{~m}$ as can be seen from Fig. 3b. Equations (1-8) were discretized using FVM Techniques. Convective term is discretized using hybrid upwind scheme. The diffusion terms are discretized using second-order central difference. Weighted average of surrounding cell-centred properties is used for determining nodal quantities. SIMPLE like algorithm is used for handling pressure velocity decoupling. Collocated grid arrangement is applied, and movement interpolation is used to determine the face flux of each cells. System of algebraic equation is solved using BICGStab. 
Fig. 4 Velocity distribution at various locations inside chamber

$(4 \mathrm{~m} \times 3 \mathrm{~m} \times 2.5 \mathrm{~m})$ for inlet supply velocity $1.36 \mathrm{~m} \mathrm{~s}^{-1}$

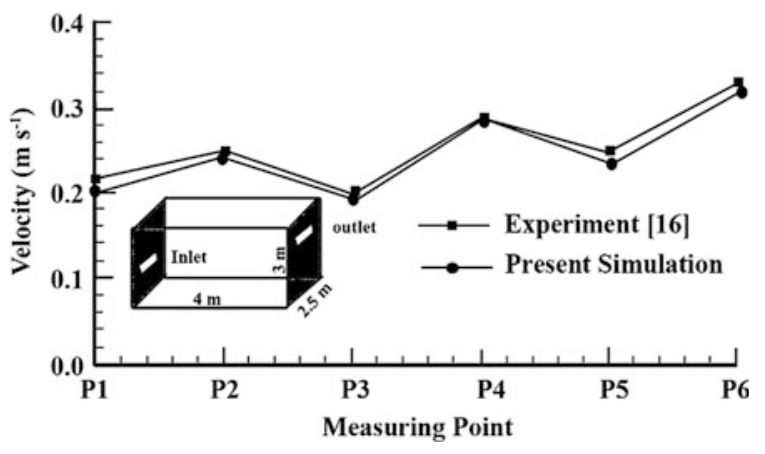

\section{Result and Discussion}

Before analysing the flow pattern of aforementioned configuration of inlet and outlet of isolated room, the present numerical methodology is validated against data available in the literature [18]. Figure 4 shows the velocity at various location of room, and it has good agreement against the experiment.

Post-validation, simulations were carried out for different cases of the isolation room. Each case has a fixed location of patient's bed in the room. In the first two cases, air supply inlet and exhaust were placed on opposite walls of the isolation room as shown earlier in Fig. 2a, b and the position of the patient bed was moved from the air supply sidewall to the exhaust sidewall. The third case had multiple air supply inlets on the ceiling of the isolation room with the exhaust on the sidewall, as shown in Fig. 2c. Further, two more cases were studied, which were sub-cases of the first two cases. In these sub-cases, the height of the air supply inlet was varied and its effect on the ventilation inside the isolation room was studied. The two inlet heights studied were $0.4572 \mathrm{~m}$ from the ceiling and $0.6096 \mathrm{~m}$ from the ceiling. In all cases, the height of the exhaust vent was $0.3048 \mathrm{~m}$ from the floor of the room.

The results of the isolation room were plotted at various planes such as $x-y$ plane $(z=1.225 \mathrm{~m})$ and $z-y$ plane $(x=1.4$ and $2.44 \mathrm{~m})$ for knowing the temperature and velocity distribution close and away to the patient. The patient body was modelled as a semi-cylindrical heat source.

Figure 5 shows the velocity and temperature contours in $x-y$ plane and $z-y$ plane of the first case study. The air supply inlet is lowered to $0.4572 \mathrm{~m}$ below the ceiling. The position of the bed of patient was near the air supply sidewall. Figure 6 shows the flow pattern in the form of velocity vectors in the in the $x-y$ plane and in the $z$ $y$ plane.

It can be observed that the zone between the patient's bed and the air jet is stagnant. However, below the bed there is comparatively better airflow due to the recirculation of the air jet that hits the exhaust sidewall, as shown in Fig. 6. Such a location of bed would be hazardous for an infectious patient because the stagnant air above the patient's bed would permit the bacteria to proliferate. However, this situation is favourable for the immune-suppressed patient since he needs to be 
(a)

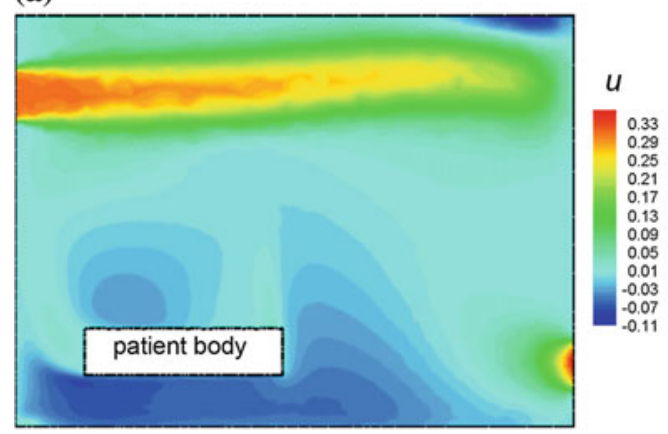

(c)

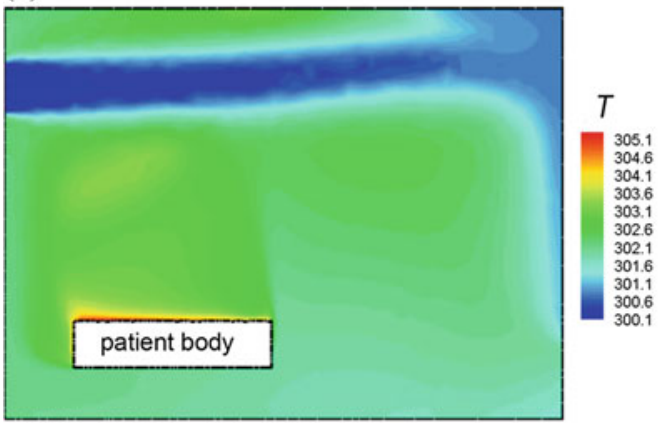

(b)

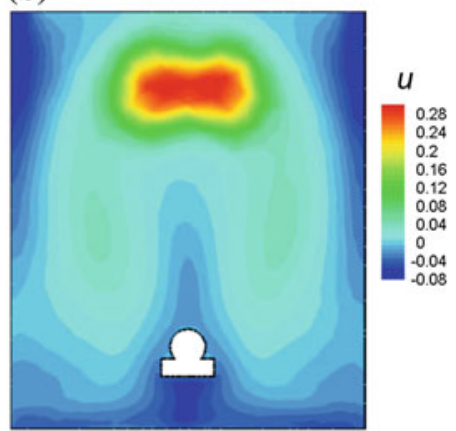

(d)

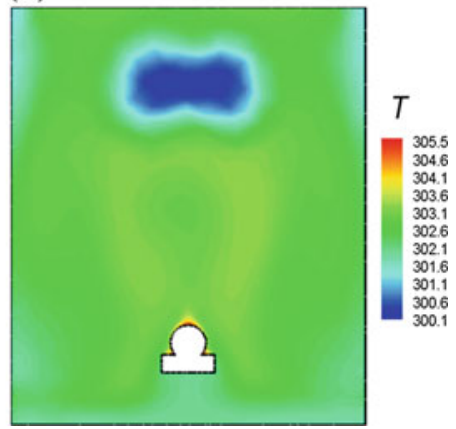

Fig. 5 X-velocity and temperature contour of isolation room in the $x-y$ plane $(z=1.525 \mathrm{~m})$ and the $z-y$ plane $(x=1.4 \mathrm{~m})$. The height of air supply inlet is $0.4572 \mathrm{~m}$ from the ceiling and the patient is close to the air supply sidewall. a, c show $u$ velocity and temperature contour in $x-y$ plane and $\mathbf{b}, \mathbf{d} u$ velocity and temperature contour in the $z-y$ plane

(a)

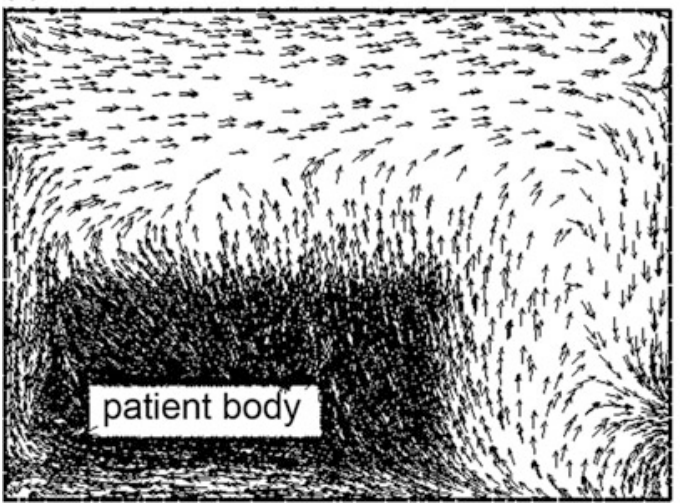

(b)

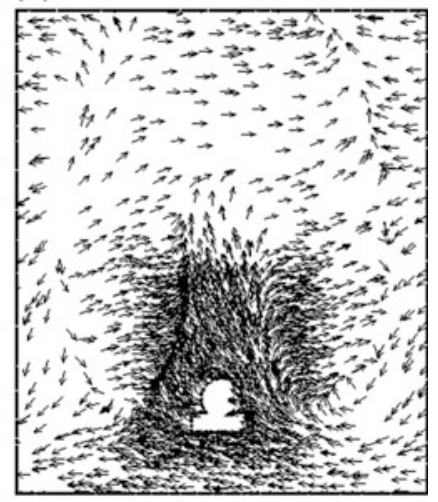

Fig. 6 Flow pattern ( $u$ and $v$ velocity vectors) of air in $\mathbf{a} x-y$ plane $(z=1.525)$ and $\mathbf{b} z-y$ plane $(x=1.4 \mathrm{~m})$ : inlet at $0.4572 \mathrm{~m}$ from the ceiling 
protected from the supply air directly hitting his body. Such an airflow field serves as a defence shield for an immune-suppressed patient. As far as the rest of the room is concerned, it is under the sole effect of supply air having a temperature of $300 \mathrm{~K}$. The air in the vicinity of the patient's body is slightly warmer than that in the rest of the space in room, as shown in Fig. $5 \mathrm{c}$, d.

Figure 7 shows the velocity and temperature contour in the $x-y$ plane and the $z$ $y$ plane. The air supply inlet is lowered to $0.6096 \mathrm{~m}$ below the ceiling. The position of the bed of patient was near the air supply sidewall. Figure 8 shows the flow pattern in the $x-y$ plane and the $z-y$ plane for this case. It can be observed that the recirculation zones above and below the bed have decreased and stagnation zones have formed. This ventilation strategy as such is not recommended for an immune-suppressed patient because he might start complaining about draught sensation. Placing an infectious patient in the room is not recommended as well due to significant stagnation zones that exist inside the room. Another recirculation zone is formed above the jet, as can be seen from Fig. 8a, and this could possibly lead to a stagnation zone above the jet further deteriorating the ventilation of the room.

(a)

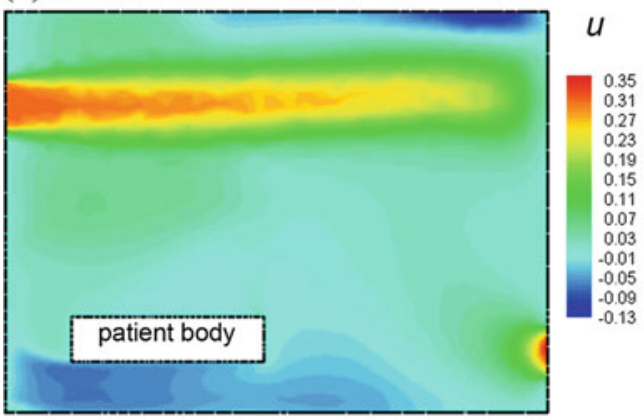

(c)

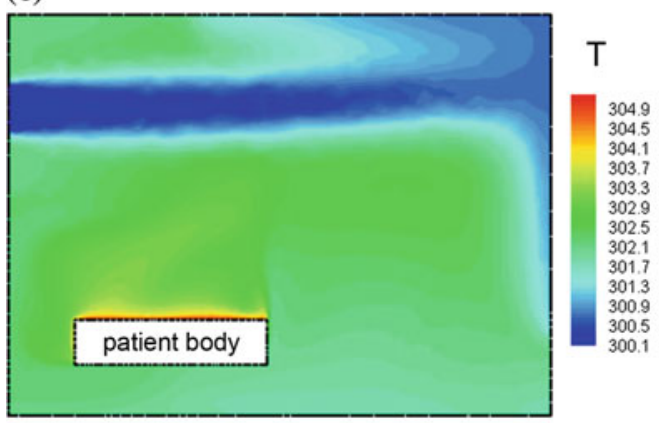

(b)

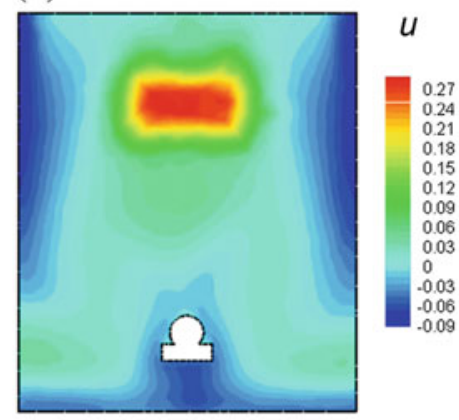

(d)

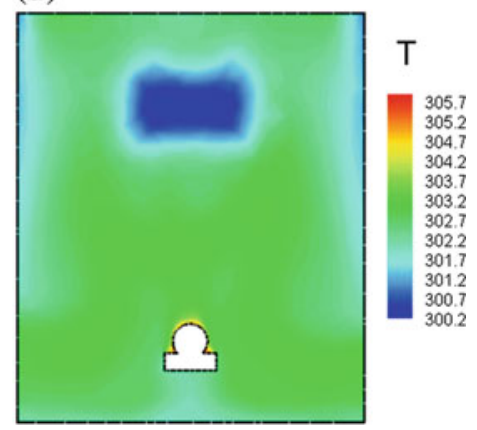

Fig. $7 \mathrm{X}$-velocity and temperature contour of isolation room in the $x-y$ plane $(z=1.525 \mathrm{~m})$ and the $z-y$ plane $(x=1.4 \mathrm{~m})$. The height of air supply inlet is $0.6096 \mathrm{~m}$ from the ceiling and the patient is close to the air supply sidewall. a, $\mathbf{c}$ show $u$ velocity and temperature contour in the $x$ $y$ plane and $\mathbf{b}, \mathbf{d} u$ velocity and temperature contour in the $z-y$ plane 
(a)

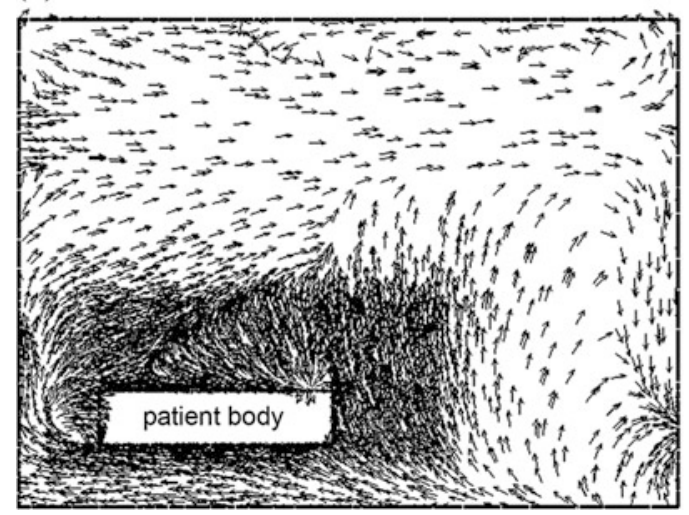

(b)

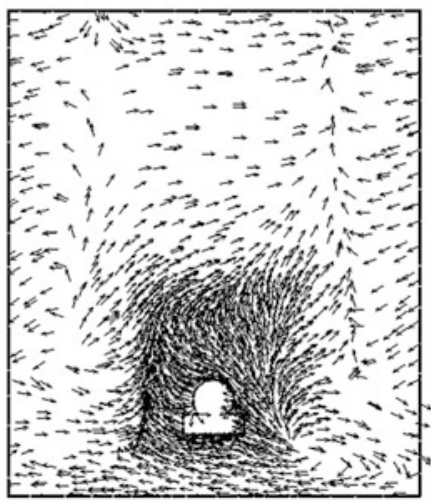

Fig. 8 Flow pattern ( $u$ and $v$ velocity vectors) of air in $\mathbf{a} x-y$ plane $(z=1.525)$ and $\mathbf{b} z-y$ plane $(x=1.4 \mathrm{~m})$ : inlet at $0.6096 \mathrm{~m}$ from ceiling

These effects can be linked to the short-circuiting of the airflow due to reduced vent height. The temperature inside the room is more evenly distributed than in the previous case.

Figure 9 shows the velocity and temperature contours in the $x-y$ plane and $z$ $y$ plane of the third case. The air supply inlet is located $0.4572 \mathrm{~m}$ below the ceiling. The position of the bed of patient was near the exhaust sidewall. Figure 10 shows the flow pattern in the form of velocity vectors in the $x-y$ plane and the $z-y$ plane.

The height of the air supply inlet is $0.6096 \mathrm{~m}$ from the ceiling and the patient is close to the exhaust sidewall. Figure $11 \mathrm{a}$, c shows $u$ velocity and temperature contour in the $x-y$ plane and Fig. $11 \mathrm{~b}, \mathrm{~d} u$ velocity and temperature contour in the $z$ $y$ plane.

The patient's body starts receiving direct air jet, which deflects down from the exhaust sidewall. However, the feet continue to be in slightly stagnant zone. There is appreciable recirculation in both the upper and lower zones of the isolation room leading to better overall ventilation. This configuration is ideal for immune-suppressed patients as the patients would typically be in a region of stagnation as shown in Fig. 9b, which would protect them from any possible infections. The draught rating would also not be very high leading to optimal configuration for the immune-suppressed patient.

Figure 12 shows the velocity and temperature contour in the $x-y$ and the $z$ $y$ plane of the fourth case. The air supply inlet was lowered to $0.6096 \mathrm{~m}$ below the ceiling. The position of the bed of patient was near the exhaust sidewall. Figure 13 shows the velocity vectors in the in the $x-y$ plane and the $z-y$ plane.

As the inlet height is lowered with the patient near exhaust sidewall, the room becomes very poorly ventilated. Although the space near the patient is agitated, there is a considerable fraction of the whole space that is experiencing stagnation in this strategy. Short-circuiting of flow would also be noticed in this case. 
(a)

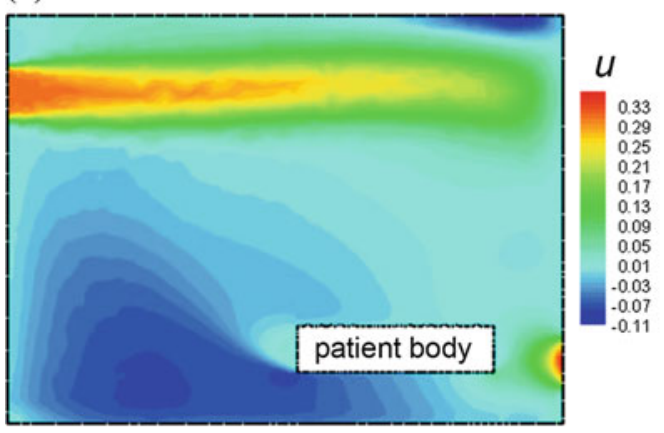

(c)

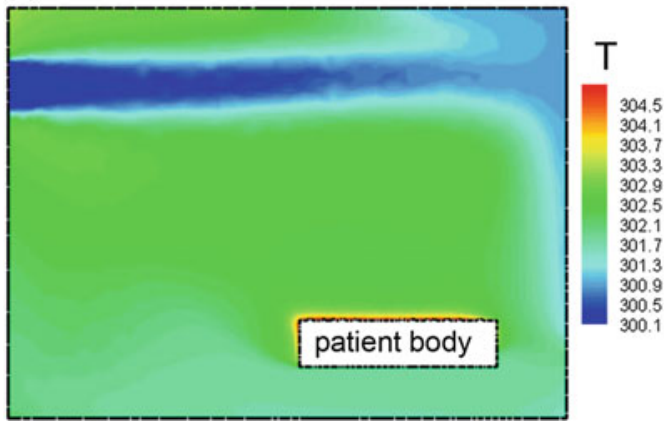

(b)

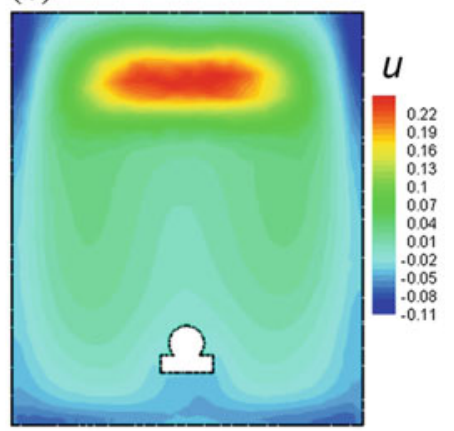

(d)

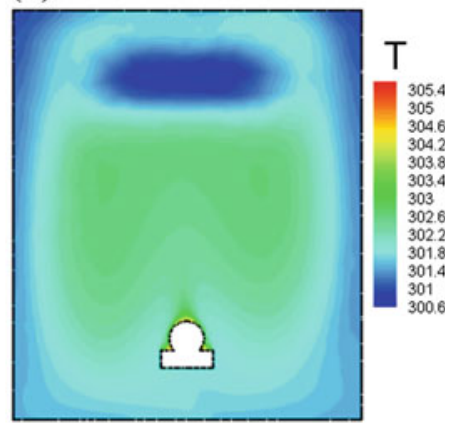

Fig. $9 \mathrm{X}$-velocity and temperature contour of the isolation room in the $x-y$ plane $(z=1.525 \mathrm{~m})$ and the $z-y$ plane $(x=1.4 \mathrm{~m})$. The height of air supply inlet is $0.4572 \mathrm{~m}$ from the ceiling, and the patient is close to exhaust sidewall. a, c show $u$ velocity and temperature contour in the $x-y$ plane and $\mathbf{b}, \mathbf{d} u$ velocity and temperature contour in the $z-y$ plane

(a)

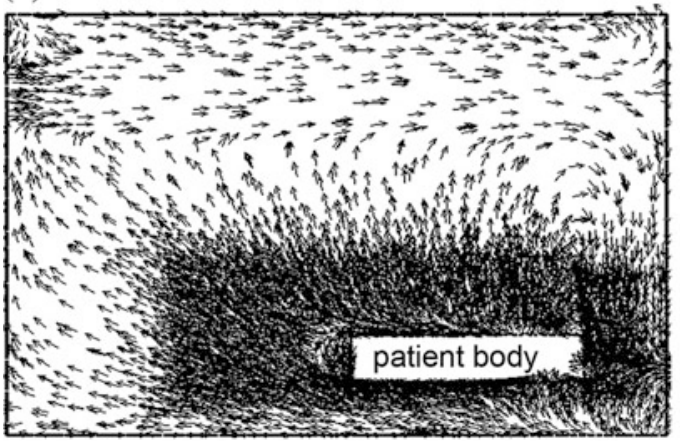

(b)

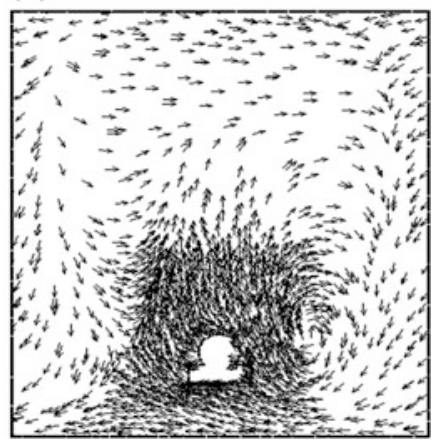

Fig. 10 Flow pattern ( $u$ and $v$ velocity vectors) of air in a $x-y$ plane $(z=1.525)$ and $\mathbf{b} z-y$ plane $(x=1.4 \mathrm{~m})$ : inlet at $0.4572 \mathrm{~m}$ from the ceiling 
(a)

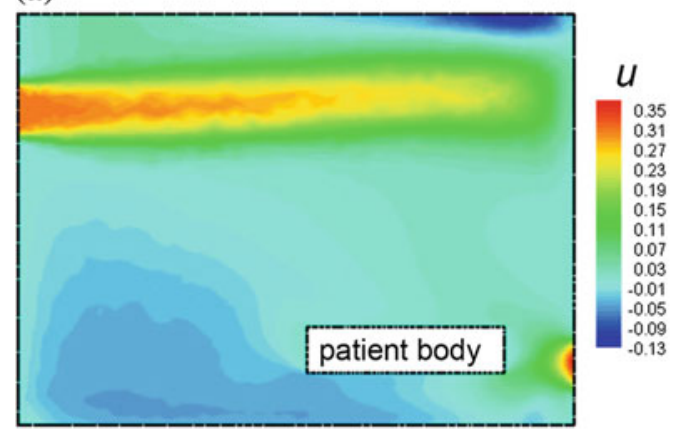

(c)

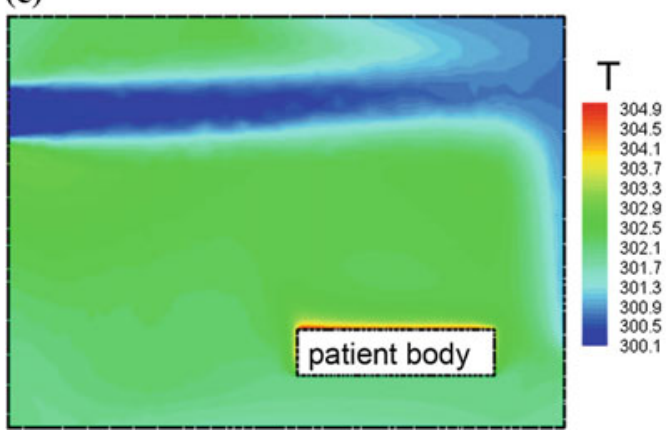

(b)

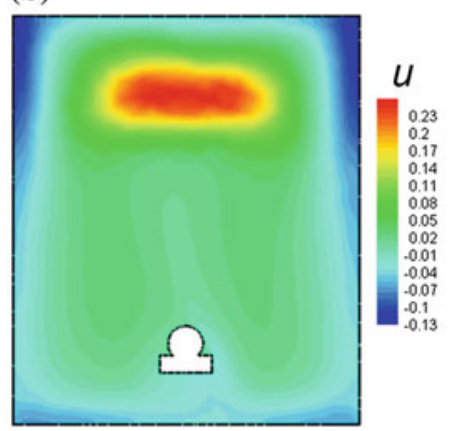

(d)

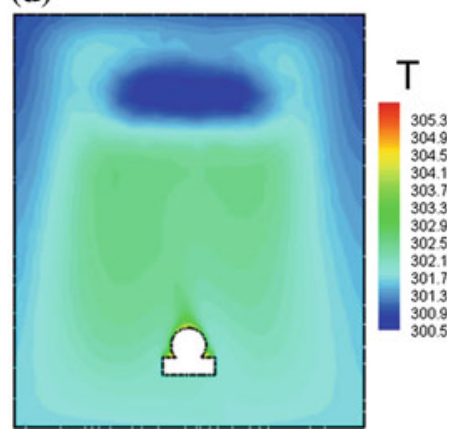

Fig. $11 x$-velocity and temperature contour of the isolation room in the $x$-y plane $(z=1.525 \mathrm{~m})$ and the $z-y$ plane $(x=1.4 \mathrm{~m})$

(a)

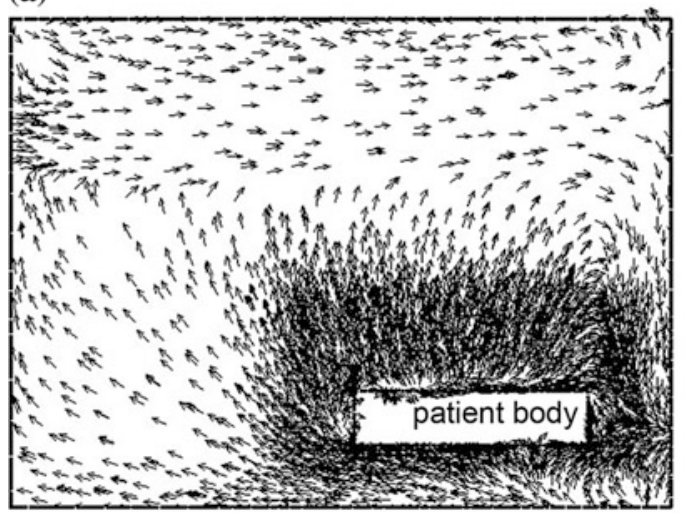

(b)

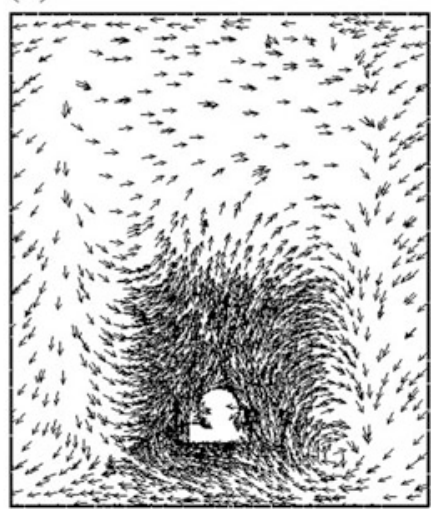

Fig. 12 Flow pattern ( $u$ and $v$ velocity vectors) of air in $\mathbf{a} x-y$ plane $(z=1.525)$ and $\mathbf{b} z-y$ plane $(x=1.4 \mathrm{~m})$ : inlet at $0.6096 \mathrm{~m}$ from ceiling 
(a)

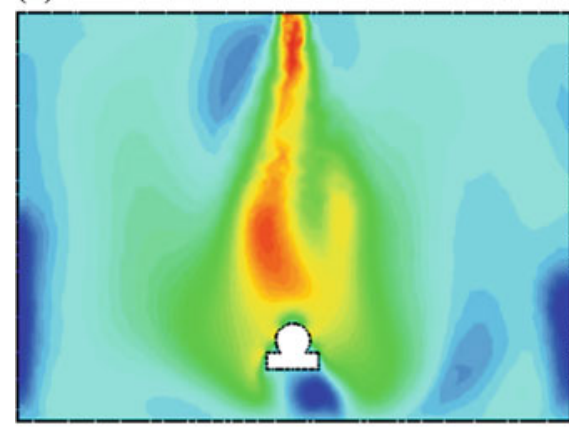

(c)

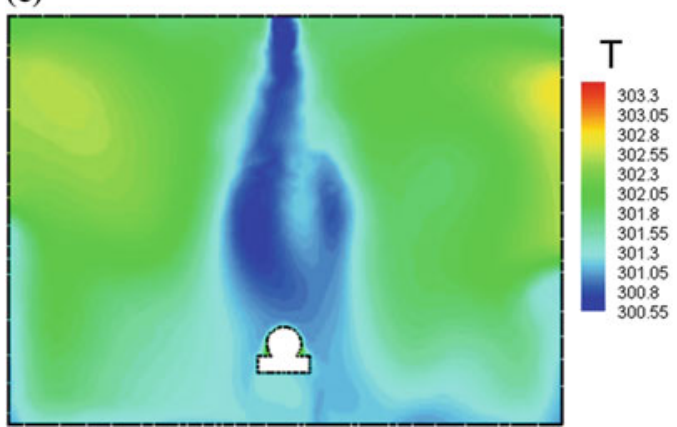

(b)

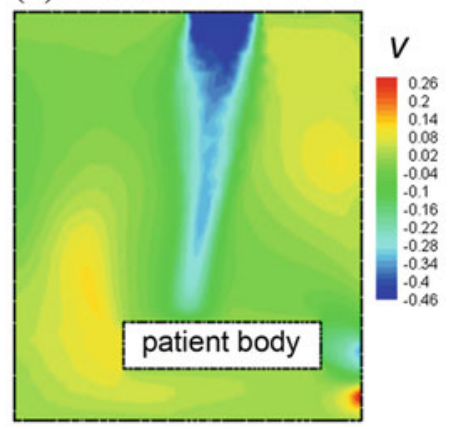

(d)

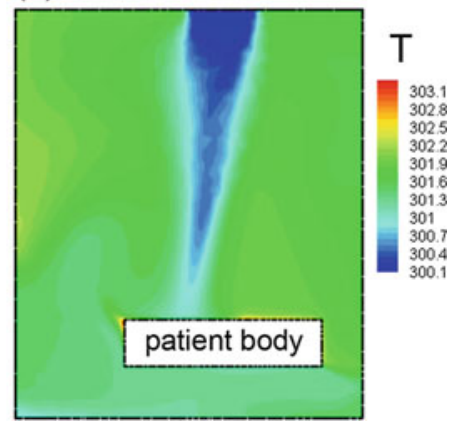

Fig. 13 y-velocity and temperature contour of the isolation room in the $x-y$ plane $(z=1.525 \mathrm{~m})$ and the $z-y$ plane $(x=2.44 \mathrm{~m})$. Three air supply inlets are located on the ceiling and the patient is close to exhaust sidewall. a, c show $v$ velocity and temperature contour in the $x-y$ plane and $\mathbf{b}$, d $v$ velocity and temperature contour in the $z-y$ plane

Figure 14 shows the velocity and temperature contour in $x-y$ and $z-y$ plane for the fifth case. Multiple air supply inlets are located on the ceiling of the isolation room. The position of the bed of patient was near the exhaust sidewall. Figure 15 shows the flow pattern in the $x-y$ and the $y-z$ plane with the air supply mounted on the ceiling.

Figure 15 shows the y-velocity profile as it develops across different levels in the $z-x$ plane. An infectious patient is advised to be kept in an isolation room provided with a mixed-ventilation system. It has multiple laminar diffusers on the ceiling, and the patient's bed is strategically located with respect to the diffusers so that the bacteria concentration is diluted effectively. The upper zone between the two symmetrically located inlet vents shows some stagnation but in the occupied zone, the air is well mixed due to the presence of two supply openings in the farther corners of the room. With multiple inlet vents, a mixed-ventilation system offers improved control over the whole airflow field inside the domain. The upper zone between the two symmetrically located inlet vents shows some stagnation but in the occupied zone, the air is well mixed due to the presence of two supply openings 
(a)

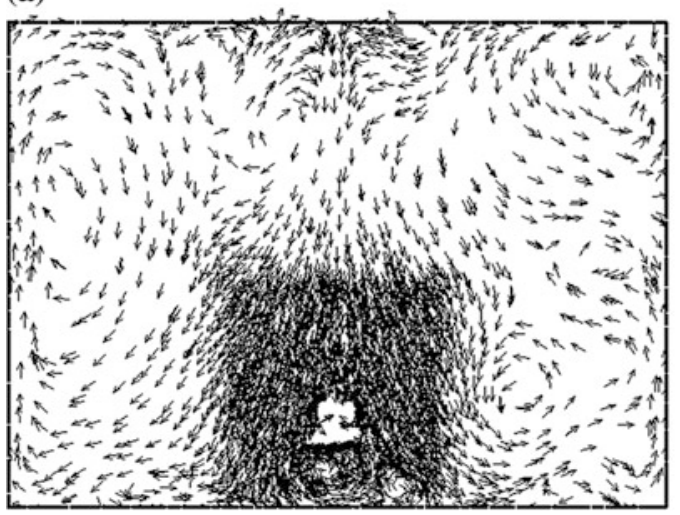

(b)

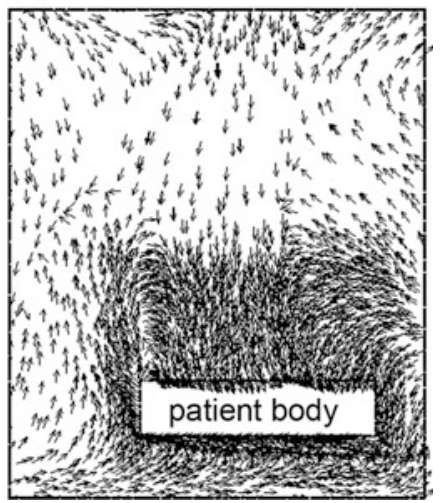

Fig. 14 Flow pattern ( $u$ and $v$ velocity vectors) of air in $\mathbf{a} x-y$ plane $(z=1.525)$ and $\mathbf{b} z-y$ plane $(x=2.44 \mathrm{~m})$

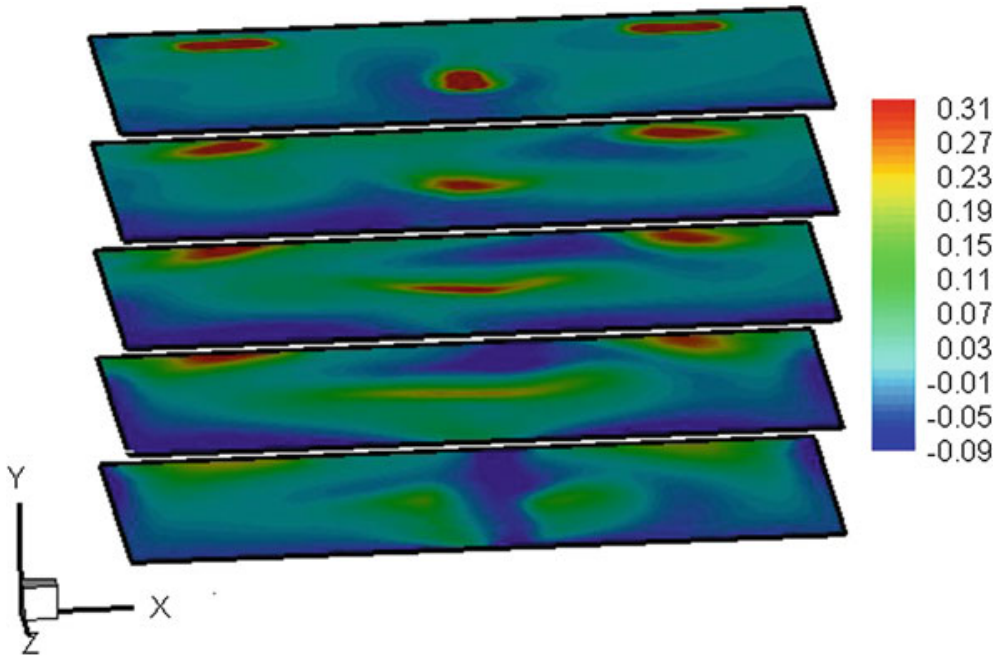

Fig. $15 \mathrm{y}$-velocity profile across the across the isolation room $(y=0.3 \mathrm{~m}$ to $y=3.3 \mathrm{~m})$

towards the corners of the room. This arrangement makes the whole room well ventilated. However, higher draught ratings must be expected in such a ventilation system. 


\section{Conclusion}

The position of the patient bed and air supply inlet of isolation room for two kinds of patients: infectious and immune-suppressed were simulated using in-house CFD solver. An immune-suppressed patient is one who is vulnerable to infection from any contaminant that accompanies the supply air. The location of the bed and the ventilation system for such a system should be designed to provide the patient maximum protection against the possible contamination in the supply air by ensuring that contaminant resident time inside the room is minimum.

The infectious patient on the other hand is one who produces infectious micro-organisms by means of breathing, coughing and sneezing. A TB or a SARS patient would be the suitable example. The ventilation system for such a patient should perform the function of flushing out the infectious bacteria as soon as they are generated. This is possible when the air flows from the less contaminated zone to the most contaminated zone.

Against this background, a mathematical model of hospital isolation room was developed and simulated. Based on the simulation results, the following conclusions can be made:

- The locations for the immune-suppressed patient inside the isolation room should be near the supply sidewall.

- An infectious patient's bed should be located near the ventilation exhaust.

- To get rid of the stagnation zones, it would be reasonable to have some constant heat sources like lamps and medical equipment inside the room so that the temperature difference causes the incoming cool air to settle down and displace the warmer air upwards via convection. In this fashion, stagnation observed in the velocity profiles for immune-suppressed patient would not be as severe.

- Mixed ventilation is a good solution for the infectious patients. It offers better control over the HVAC and ventilation parameters due to the multiple inlet vents.

- In this study, many simplifications/assumptions were taken that render our results only approximate. For our research to aide in the practical design of a hospital isolation ward or operation theatre, these approximations must be reduced and a model as exact as computationally possible, must be developed.

\section{References}

1. Phillips DA, Sinclair RJ, Schuyler GD (2004) Isolation room ventilation. Design case studies. In: Proceedings of IAQ conference, ASHRAE

2. Health Canada, Guidelines for preventing the transmission of tuberculosis in Canadian health care facilities and other institutional settings. Engineering controls to minimize TB transmission. Canada Communicable Disease Report 1996; 22S1 
3. http://www.vox.com/2016/5/31/11638796/why-there-are-more-infectious-disease-outbreaks

4. Memarzadeh F (2011) Literature review of the effect of temperature and humidity on viruses that cause epidemics \& pandemics. ASHRAE Trans 117(2):24-37

5. ASHRAE, HVAC Design Manual for Hospitals and Clinics 2013. American Society of Heating, Refrigerating and Air-Conditioning Engineers, Atlanta

6. Department of Human Services (1999) Guidelines for the classification and design of isolation rooms in health care facilities. Standing Committee on Infection Control, Victoria, Australia

7. Conroy LM, Franke JE, Dimos J, Vittallo JA, Lee SC (1997) Ventilation survey of tuberculosis isolation rooms in five hospitals. In: Ventilation '97, Proceedings of the 5th international symposium on ventilation for contaminant control, vol 9, issue 1

8. Guidelines for the classification and design of isolation rooms in health care facilities, 2007

9. CDC (2005) Guidelines for preventing the transmission of mycobacterium tuberculosis in health-care settings. Morb Mortal Wkly Rep (MMWR) 54(17):1-141

10. Cheong KWD, Phua SY (2006) Development of ventilation design strategy for effective removal of pollutant in the isolation room of a hospital. Build Environ 41:1161-1170

11. Memarzadeh F, Xu W (2012) Role of air changes per hour (ACH) in possible transmission of airborne infections. Build Simul 5(1):15-28

12. Mousavi ES, Grosskopf KR (2015) Ventilation rates and airflow pathways in patient rooms: a case study of bioaerosol containment and removal. Ann Occup Hyg 5(9):1190-1199

13. Walker JT, Hoffman P, Bennett AM (2007) Hospital and community acquired infection and the built environment - design and testing of infection control rooms. J Hosp Infect 65:43-49

14. Tung Y-C, Hu S-C, Tsai T-I, Chang I-L (2009) An experimental study on ventilation efficiency of isolation room. Build Environ 44(2):271-279

15. Derakhshan S, Shaker A (2016) Numerical study of the cross-ventilation of an isolated building with different opening aspect ratios and locations for various wind directions. Int J Vent

16. Wan JW, Yang K, Zhang WJ, Zhang J (2009) A new method of determination of indoor temperature and relative humidity with consideration of human thermal comfort. Build Environ 44(2):411-417

17. Beggs CB, Kerr KG, Noakes CJ, Hathway EA, Sleigh PA (2016) The ventilation of multiple-bed hospital wards: review and analysis. Am J Infect Control 36(4):250-259

18. Chung K-C, Hsu S-P (2001) Effect of ventilation pattern on room air and contaminant distribution. Build Environ 36(9):989-998

19. Yu HC, Mui KW, Wong LT, Chu HS (2016) Indoor and built ventilation of general hospital wards for mitigating infection risks of three kinds of viruses including Middle East respiratory syndrome coronavirus. Indoor Built Environ 1-14

20. Xu Z, Zhou B (2016) Dynamic isolation technologies in negative pressure isolation wards. Springer, Beijing

21. Bivolarova MP, Melikov AK, Mizutani C, Kajiwara K, Bolashikov ZD (2016) Bed-integrated local exhaust ventilation system combined with local air cleaning for improved IAQ in hospital patient rooms. Build Environ 100:10-18

22. Cao G, Awbi H, Yao R, Fan Y, Sirén K, Kosonen R, Zhang J (2014) "SC," Build Environ

23. Peren JI, Van Hooff T, Leite BCC, Blocken B (2014) CFD analysis of cross-ventilation of a generic isolated building with asymmetric opening positions: impact of roof angle and opening location. $31: 1-21$

24. Sikarwar BS, Khandekar S, Muralidhar K (2013) Simulation of flow and heat transfer inside a liquid drop sliding underneath a hydrophobic surface. Int J Heat Mass Transf 57(2):786-811

25. AIA (2006) Guidelines for design and construction of health care facilities, 2nd edn. The American Institute of Architects, Washington, DC

26. Siegel JD, Rhinehart E, Jackson M (2007) 2007 guideline for isolation precautions: preventing transmission of infectious agents in healthcare settings. Am J Infect Control 35: S65-S124

27. ASHRAE (2008) Standard, 170-2008 Ventilation of health care facilities. ASHRAE, Atlanta, GA

28. Atkinson J, Chartier Y, Pessoa-Silva CL (2009) Natural ventilation for infection control in health-care settings. World Health Organization. ISBN 9789241547857 
29. ASHRAE. Handbook of Fundamentals 1997. American Society of Heating, Refrigeration and Air Conditioning Engineers, Inc., Atlanta

30. http://www.physics.usyd.edu.au/teach_res/db/d005c.htm

31. McDowall R (1987) Fundamentals of HVAC systems. American Society of Heating, Refrigerating and Air-Conditioning Engineers Inc., Atlanta

32. Launder BE, Spalding DB (1972) Lectures in mathematical models of turbulence. Academic Press, London; New York 